\title{
Research Article Constructing a Small-Region DSGE Model
}

\author{
Kenichi Tamegawa \\ School of Commerce, Meiji University, 1-1 Kanda-Surugadai, Chiyoda-ku, Tokyo 101-8301, Japan \\ Correspondence should be addressed to Kenichi Tamegawa; tamegawa@kisc.meiji.ac.jp
}

Received 8 January 2013; Accepted 3 February 2013

Academic Editors: B. Junquera, M. E. Kandil, A. Rodriguez-Alvarez, M. Tsionas, and A. Watts

Copyright ( 2013 Kenichi Tamegawa. This is an open access article distributed under the Creative Commons Attribution License, which permits unrestricted use, distribution, and reproduction in any medium, provided the original work is properly cited.

This paper constructs a tractable dynamic stochastic general equilibrium (DSGE) model of a regional economy that is considered small because it does not affect its national economy. To examine properties of our small-region DSGE model, we conduct several numerical simulations. Notably, fiscal expansion in our model is larger than that in standard DSGE models. This is because the increase in regional output does not raise interest rates, and this leads to the crowding-in effects of investment.

\section{Introduction}

Economists and central banks frequently use dynamic stochastic general equilibrium (DSGE) models to analyze macroeconomies and to evaluate economic policy. While DSGE models that analyze macro economies have been increasingly developed, a DSGE model to analyze a regional economy such as a prefecture in Japan, a state in the United States, or a county in the United Kingdom is needed. There are numerous small regions in which that output is a small fraction of GDP. Twenty-two of fifty-one states in the USA produced less than 1\% of its GDP in 2010. In Japan, nineteen of forty-seven prefectures produced less than $1 \%$ of Japan's GDP in 2010. Small regions' policy makers need an effective small-region DSGE model to evaluate their policies, or they will be forced to use traditional macro-econometric models.

We aim to construct a tractable DSGE model to analyze a small region that does not affect its national economy because a model for a large region can be constructed using standard DSGE models. Our model can forecast a targeted small region's economy, given various national economic variables such as GDP, and it can evaluate effects of local and central government policies on the region. In particular, our model is quite useful for regional policy planning.

From a theoretical point of view, in our small-region DSGE model, the region's activity does not alter both of the interest rates of financial assets and final goods prices, which are affected by changes in state of national economy. In particular, a constancy of interest rates has great importance for fiscal policy in our model because crowding-out effects for both consumption and investment then disappear. Fiscal expansion usually has negative effects on consumption due to negative income effects and intertemporal substitution effects (see Baxter and King [1]). The decrease in investment results in an increase in interest rates. In our model, since crowding-out effects are completely muted, fiscal expansion tends to yield a large positive effect on the economy without additional assumptions. In order to obtain a positive consumption response to fiscal shock, several assumptions are suggested: "deep habit" (Ravn et al. [2]), a utility function that strengthens the complementarity between consumption and labor (Linnemann [3] and Monacelli et al. [4]), and nonRicardian households (Galí et al. [5]). Recently, Christiano et al. [6] showed that large multipliers are obtained, if interest rates are at zero lower bound. Further, our model allows for the existence of counter-cyclical markup. Therefore, the fiscal multiplier becomes large if agents in the small region do not utilize their resources to buy the goods produced by rest of regions. Recently, Beetsma and Giuliodori [7] confirm that the fiscal multipliers are larger than one. While this feature of fiscal policy would not be new in terms of small-open DSGE models with the fixed exchange rate system like the traditional Mundell-Fleming model, this response for fiscal policy stands in a stark contrast to standard single-country DSGE models. In a small-open model with a fixed exchange regime, fiscal policy becomes effective, but monetary policy does not. However, in our small-region DSGE model, monetary policy can also be effective. Further, 
our model differs from small-open models in that in our model, there is a central government. Therefore, either the local or the central government can implement fiscal policy and one can analyze whether the effects of fiscal policy differ between local and central governments.

The model we construct in this paper can be interpreted as a variant of a small-open DSGE model. Intuitively, our model is a small-open model that is free from the trilemma in international economics if one understands ours in the framework of a small-open economy. There have been many DSGE-oriented papers focusing on modeling a small-open country. For example, Christiano et al. [8] constructed a small-open DSGE model that incorporates unemployment and financial constraints and uses it to estimate Sweden's economy. Furthermore, Adolfson et al. [9] have estimated an open economy DSGE model according to Christiano et al. [8] in the euro area. Cakici [10] examined the effects of financial integration on business cycles for a small-open economy and found that a higher degree of integration amplifies the effects of monetary policy shock. De Paoli [11] has investigated optimal monetary policy in a small-open economy and has shown that the optimal monetary policy rule differs according to the elasticity of substitution between domestic and foreign goods.

The organization of the rest of this paper is as follows. Section 2 explains agents' behavior and constructs a general equilibrium model. Section 3 sets parameters, while Sections 4 and 5 simulate our model to examine its properties. Finally, Section 6 concludes this paper.

\section{The Model}

We assume that in a small region, there are households, wholesale goods producers, retail goods producers, and a local government. These agents decide their behavior given macroeconomic states (GDP and nominal interest rate for financial assets). Further, we assume that this region's economy is small such that it does not affect national economy and that there is no intraregion immigration. The latter assumption implies that labor market is closed in this region.

2.1. Wholesale Firms. Under perfect competition, wholesale firms produce wholesale goods with the following CobbDouglas technology:

$$
y_{t}=e^{z_{t}}\left(k_{t}\right)^{\alpha}\left(n_{t}\right)^{1-\alpha}
$$

where $y_{t}$ denotes output, $k_{t}$ capital stock, $n_{t}$ labor, and $z_{t}$, technology shock with mean 0 . The firms hire labor to maximize the following profits:

$$
\max _{n_{t}} \frac{P_{t}^{w}}{P_{t}} y_{t}-w_{t} n_{t}-r_{t} k_{t},
$$

where $P_{t}^{w}$ denotes wholesale goods price, $P_{t}$ final goods price, $w_{t}$ real wage rate, and $r_{t}$ real rental rate of capital stock. The first-order condition is

$$
w_{t}=(1-\alpha) \frac{y_{t}}{x_{t} n_{t}} .
$$

The rental rate is equal to the following profit rate:

$$
r_{t}=\alpha \frac{y_{t}}{x_{t} k_{t}}
$$

where $x_{t}=P_{t} / P_{t}^{w}$.

2.2. Retailers. Retailers indexed by $i \in[0,1]$ convert one unit of wholesale goods to one unit of final goods. We assume that retailers are in monopolistic competition with Calvos [12] (1983) type of sticky price setting. However, the region in this paper is small, and as such, the national final goods price level is not affected by the price setting behavior of this region's retailers.

2.3. Households. Households decide their consumption $\left\{c_{t}\right\}$ and labor supply $\left\{n_{t}\right\}$ along with the following optimization problem:

$$
\begin{gathered}
\max \quad E_{0} \sum_{t=0}^{\infty} \prod_{s=0}^{t} \Xi_{s}\left\{\log \left(c_{t}\right)-\chi \frac{\left(n_{t}\right)^{1+\eta}}{1+\eta}\right\}, \\
\text { s.t. } \quad \frac{a_{t+1}+m_{t+1}}{P_{t}} \\
=\frac{R_{t-1}^{n} a_{t}+m_{t}}{P_{t}}+r_{t} k_{t}+r_{t}^{r r} k_{t}^{r r}+\prod_{t} \\
\quad+w_{t} n_{t}-t_{t}-t_{t}^{c}-c_{t}-i_{t}-i_{t}^{r r}, \\
k_{t+1}=(1-\delta) k_{t}+\Phi\left(\frac{i_{t}}{i_{t-1}}\right) i_{t}, \\
k_{t+1}^{r r}=(1-\delta) k_{t}^{r r}+\Phi\left(\frac{i_{t}^{r r}}{i_{t-1}^{r r}}\right) i_{t}^{r r},
\end{gathered}
$$

where $a_{t}$ denotes nominal deposits, $m_{t}$ nominal money holdings, $R_{t}^{n}$ gross nominal returns on deposits, $r_{t}^{r r}$ profit rate of the remaining regions' retailers $k_{t}^{r r}$ capital stock of the rest of regions, $\Pi_{t}$ excess profits of retailors, $t_{t}$ lump sum tax for local government, $t_{t}^{c}$ lump-sum tax for central government, $i_{t}$ investment for local wholesales firms, and $i_{t}^{r r}$ investment for the remaining wholesale firms. $\Phi\left(i_{t} / i_{t-1}\right)$ represents the adjustment costs with $\Phi(1)=1$ and $\Phi^{\prime}(1)=$ 0 . In the above objective function, $\Xi_{t}$ denotes a timedependent discount factor, and we define $\Xi_{t}=\beta\left(\bar{c}_{t}\right)^{2}$, where $\bar{c}_{t}$ represents average consumption as in the case of external consumption habit. This is needed to close the model as in small-open models. (In detail, in a small economy, the standard consumption Euler equation yields a random walk process for consumption. For this problem, SchmittGrohé and Uribe [13] suggest several remedies. We take the assumption of an endogenous discount rate as known Uzawa preference while ours is external). While $\bar{c}_{t}$ can be replaced by $c_{t}$, which is a control variable, we take it as external for simplicity. 
The first-order conditions that are needed to construct our model are

$$
\begin{gathered}
E_{t}\left[\frac{\Xi_{t+1} R_{t}^{n} c_{t}}{c_{t+1}\left(P_{t+1} / P_{t}\right)}\right]=1, \\
w_{t}=c_{t} \chi\left(n_{t}\right)^{\eta}, \\
q_{t}=E_{t}\left[\Lambda_{t+1, t}\left(r_{t+1}+(1-\delta) q_{t+1}\right)\right], \\
q_{t}\left\{1-\Phi^{\prime}\left(\frac{i_{t}}{i_{t-1}}\right)\left(\frac{i_{t}}{i_{t-1}}\right)-\Phi\left(\frac{i_{t}}{i_{t-1}}\right)\right\} \\
+E_{t}\left(\frac{\Lambda_{t+1, t} q_{t+1} \Phi^{\prime}\left(i_{t+1} / i_{t}\right)\left(i_{t+1} / i_{t}\right)^{2}}{P_{t+1} / P_{t}}\right) \\
=1,
\end{gathered}
$$

where $\Lambda_{t+1, t}=\Xi_{t+1}\left(c_{t} / c_{t+1}\left(P_{t+1} / P_{t}\right)\right)$ denotes a stochastic discount factor.

2.4. Government. The local government in our small region spends $g_{t}^{L}$ and collects a lump-sum tax. If the tax is not enough to cover spending, they issue government bond $b_{t}$ with gross nominal interest rate $R_{t}^{b}$. This implies that the government bond accumulates as follows:

$$
b_{t+1}=\frac{R_{t-1}^{b}}{\left(P_{t} / P_{t-1}\right)} b_{t}+\left(g_{t}^{L}-t_{t}\right) .
$$

We assume that the local government bond rate is related to deposit rates in following manner:

$$
\log R_{t}^{b}=\text { const. }+\log R_{t}^{n}+\rho_{R} \log b_{t+1},
$$

where $\rho_{R} \log b_{t+1}$ represents a risk premium and "const." denotes the value that is consistent with the steady state value. For the budget constraint in the local government to be sustainable, we assume the following tax rule:

$$
\log t_{t}=\text { const. }+\rho_{\operatorname{tax}} \log b_{t} .
$$

Local government spending is defined as follows:

$$
\log g_{t}^{L}=\text { const. }+\rho_{g, L} \log g_{t-1}^{L}+\varepsilon_{t}^{L} .
$$

In our model, the central government can consume the small region's goods denoted by $g_{t}^{L}$ and this is defined as follows:

$$
\log g_{t}^{C}=\text { const. }+\rho_{g, C} \log g_{t-1}^{C}+\varepsilon_{t}^{C} .
$$

2.5. Net Export. We assume that export log-linearly depends on GDP $Y_{t}$ with coefficient $\rho_{Y}$. Assuming that the households and government have the following preferences for their own region's and remaining regions' final goods $\left(c_{t}^{r r}\right)^{\rho_{c}}\left(c_{t}^{s}\right)^{1-\rho_{c}}$, $\left(i_{t}^{r r}\right)^{\rho_{i}}\left(i_{t}^{s}\right)^{1-\rho_{i}}$, and $\left(g_{t}^{r r}\right)^{\rho_{g}}\left(g_{t}^{s}\right)^{1-\rho_{g}}$, and that they maximize utility subject to $c_{t}^{r r}+c_{t}^{s}=c_{t}, i_{t}^{r r}+i_{t}^{s}=i_{t}$, and $g_{t}^{r r}+g_{t}^{s}=g_{t}^{L}+g_{t}^{c}$, we have the following net export function:

$$
\begin{array}{r}
n x_{t}=\rho_{Y} Y_{t}-\rho_{c} c_{t}-\rho_{i} i_{t}-\rho_{g} g_{t}, \\
\rho_{Y}, \rho_{c}, \rho_{i}, \rho_{g} \in[0,1],
\end{array}
$$

where $c_{t}^{s}$ and $c_{t}^{r r}$ represent a small region's real consumption and a remaining regions consumption, respectively. They are defined by the following Lebesgue integral, denoting $c_{t}(i)$ as consumption for good $j$

$$
\begin{gathered}
c_{t}^{s}=\int_{S} \frac{p_{t}(j)}{P_{t}} c_{t}(j) d j, \\
c_{t}^{r r}=\int_{[0,1] / S} \frac{p_{t}(j)}{P_{t}} c_{t}(i) d j,
\end{gathered}
$$

$S=\{j \in[0,1] \mid$ a good $j$ is produced by the small region $\}$,

$i_{t}^{r r}, i_{t}^{s}, g_{t}^{r r}$, and $g_{t}^{s}$ are also defined in a similar way. If $\rho_{c}$, $\rho_{i}$, and $\rho_{g}$ are equal to 1 , then the underlying small region's goods are bought from the remaining regions. Therefore, these parameters represent leakage from the small region to the remaining regions.

2.6. Equilibrium Condition. Our small-region model has three markets (labor market, wholesale goods market, and final goods market). The labor market equilibrium is expressed using (3) and (6) as follows:

$$
c_{t} \chi\left(n_{t}\right)^{\eta}=(1-\alpha) \frac{y_{t}}{x_{t} n_{t}} .
$$

The wholesale goods market is in equilibrium, once the final goods market is in equilibrium as follows:

$$
y_{t}=c_{t}+i_{t}+g_{t}+n x_{t},
$$

where $g_{t}=g_{t}^{L}+g_{t}^{c}$.

2.7. Macroeconomy Part. The exogenous macroeconomic variables in the above small-region DSGE model are $Y_{t}$, $P_{t}$, and $R_{t}^{n}$. Although we can take these variables simply as being exogenous, we have to take care that they are mutually affected in the general equilibrium. Therefore, if one wants to simulate the effects of national level shocks on the small region's economy, one must construct a macroeconomic model.

To endogenize macroeconomic variables, for simplicity, we use the dynamic IS-LM model, which consists of three equations: dynamic IS curve (the Euler equation), dynamic LM curve (the Taylor rule), and new-Keynesian Philips curve. Of course, we can also utilize a full blown DSGE model such as Christiano et al. [14]. Typically, the dynamic IS-LM model is expressed as follows:

$$
\begin{gathered}
E_{t}\left[\widehat{Y}_{t+1}\right]+E_{t}\left[\widehat{\pi}_{t+1}\right]=\widehat{Y}_{t}+\widehat{R}_{t}^{n}, \\
\widehat{\pi}_{t}=\beta E_{t}\left[\widehat{\pi}_{t+1}\right]+\kappa \widehat{Y}_{t}+\varepsilon_{t}^{s}, \\
\widehat{R}_{t}^{n}=\Psi \widehat{\pi}_{t}+\varepsilon_{t}^{R},
\end{gathered}
$$

where " $\wedge$ " denotes the deviation from the steady state value and $\varepsilon_{t}^{s}$ and $\varepsilon_{t}^{R}$ are supply shock and monetary policy shock, respectively. These are all i.i.d. random shocks with mean 0 . 

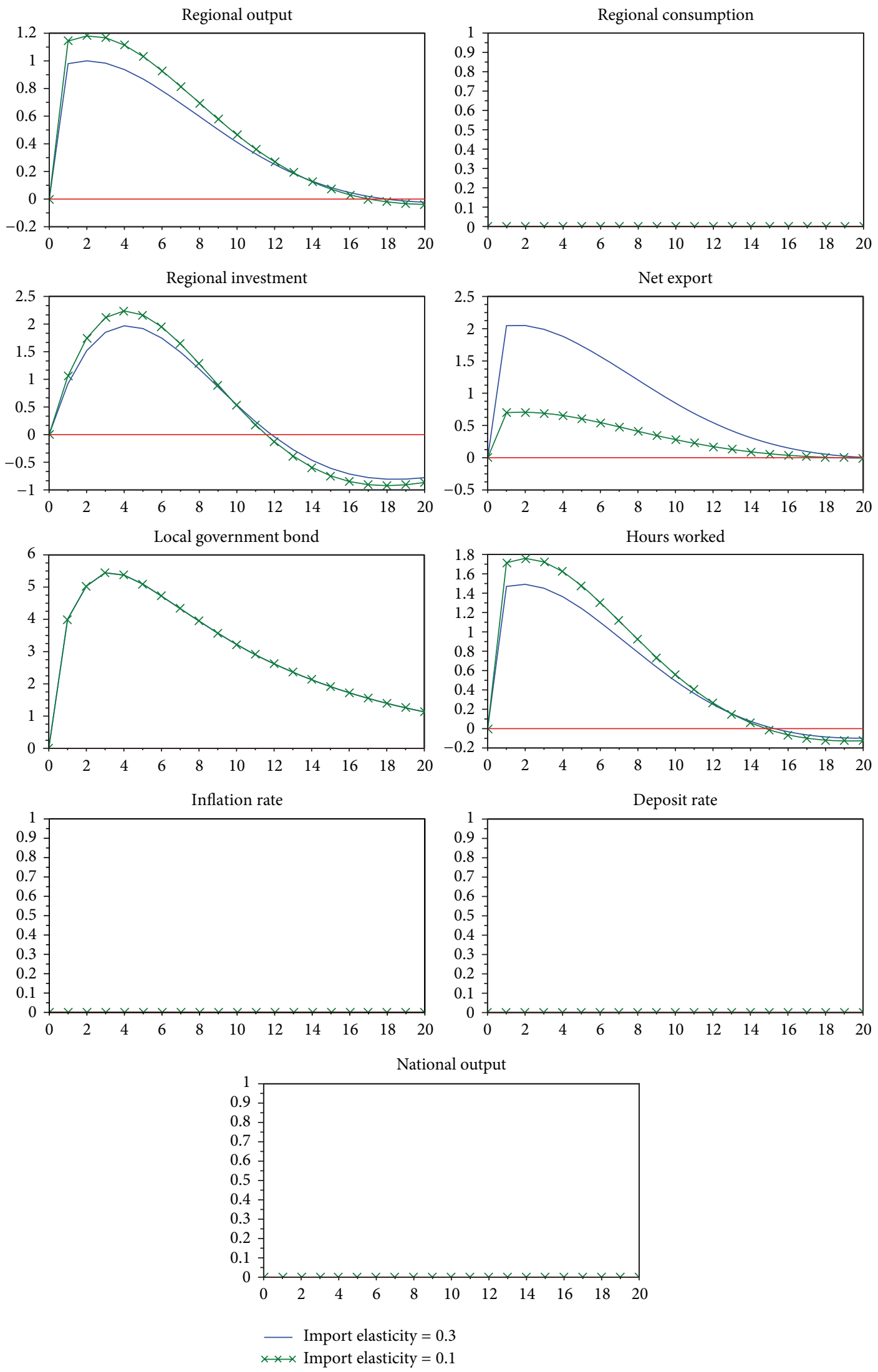

FIGURE 1: Impulse responses to the local government spending shock. Note: each line represents a percentage deviation from the steady state value. 


\section{Parameter Settings}

Assuming that the time interval of the mode is quarter, we set the parameters following Levin et al's [15] estimates: consumption share $=0.56$, government-expenditure share $=$ 0.2 , capital share $=1 / 3$, discount rate $=0.99$, and capital depreciation rate $=0.025$. We set central government's spending share at 0.1 . The steady state value of output is normalized to 1 . The adjustment cost function is assumed as $\Phi\left(i_{t} / i_{t-1}\right)=$ $1-(\phi / 2)\left(i_{t} / i_{t-1}-1\right)^{2}$ and we set $\phi=1.79$. Further, following these estimates, we set $\eta=1.49$ and implicitly calculated $\kappa=$ 0.037 .

The remaining parameters should be estimated to match actual data in the underlying region. However, this paper is not intended to analyze the specific region. Therefore, we assign potentially possible value to those parameters. The debt in the steady state is set at one (the debt-to-GDP ratio is 0.25 ). The elasticity of lump-sum tax with respect to debt is 0.9 . The steady state value of net export is set at -0.1 because small regions tend to be net importers (e.g. Japan's prefectural data in 2010 shows that about $80 \%$ of the prefectures, whose gross prefectural product was less than $1 \%$ of GDP, were net importers.) The import elasticity, which can be expressed as $\left|\rho_{c}(c / n x)\right|,\left|\rho_{i}(i / n x)\right|$, and $\left|\rho_{g}(g / n x)\right|$ where the lower letter denotes the steady state values, are set at 0.1 or 0.3 . This parameterization implies that a $1 \%$ increase in each demand leads to $0.1 \%$ or $0.3 \%$ increase in import. Therefore, these numbers express "leakage" of demand from the small region to other regions. Similar to import elasticity, export elasticity $\left|\rho_{Y}(Y / n x)\right|$ is set at 0.1 or 0.3 .

The parameter for monetary policy rule $\Psi$ is set at 1.5 . The parameter $\iota$, which is needed to close the model, is set at 0.01 . The assumed parameters are listed in Table 1.

\section{Effects of Fiscal Policy}

Typically, a local government is interested in the effects of fiscal policy because local spending is its control variable at least in terms of economic models. Therefore, we simulate the effects of fiscal policy in this section. The simulation of other shocks is postponed to the next section.

4.1. Local Government's Spending Shock. Figure 1 shows the impulse responses to the local government's spending shock $\varepsilon_{t}^{L}$ in (10), which is arranged to $1 \%$ of its output. Since the interest rate is unchanged, the consumption response is completely muted. However, the fiscal multiplier is larger than 1 because the counter cyclical markup $x_{t}$ boosts labor demand and investment demand. Thus, government spending has crowding-in effects on investment. (Empirical results in Beetsma and Giuliodori [7] show crowding in for investment.) This property is not obtained in standard DSGE models.

However, the larger the value of the parameter representing leakage of demand is, the smaller the fiscal multiplier is. Therefore, for calculating the effects of government spending in small-region settings, the leakage parameters are considerably important. As additional information, we calculate the fiscal multiplier under several values of import
TABLE 1: Parameter settings.

\begin{tabular}{lcc}
\hline Notation & Description & Value \\
\hline$c / y$ & Consumption share & 0.56 \\
$g / y$ & gvmt-ex share & 0.2 \\
$\alpha$ & Capital share & $1 / 3$ \\
$\beta$ & Discount rate & 0.99 \\
$\delta$ & Capital depreciation rate & 0.025 \\
$\phi$ & Adjustment cost & 1.79 \\
$\eta$ & Utility function & 1.49 \\
$\kappa$ & NKPC & 0.037 \\
$b / y$ & Bond share & 0.25 \\
$n x / y$ & Net export share & -0.1 \\
$\rho_{\operatorname{tax}}$ & Tax elasticity & 0.9 \\
$\rho_{g, L}$ & Local gvt-ex elasticity & 0.9 \\
$\rho_{g, C}$ & Central gvt-ex elasticity & 0.9 \\
$\left|\rho_{c}(c / n x)\right|$ & Import elasticity & 0.1 or 0.3 \\
$\left|\rho_{i}(i / n x)\right|$ & Import elasticity & 0.1 or 0.3 \\
$\left|\rho_{g}(g / n x)\right|$ & Import elasticity & 0.1 or 0.3 \\
$\left|\rho_{Y}(Y / n x)\right|$ & Import elasticity & 0.1 or 0.3 \\
$\Psi$ & Monetary policy rule & 1.5 \\
$\iota$ & Closing parameter & 0.01 \\
\hline
\end{tabular}

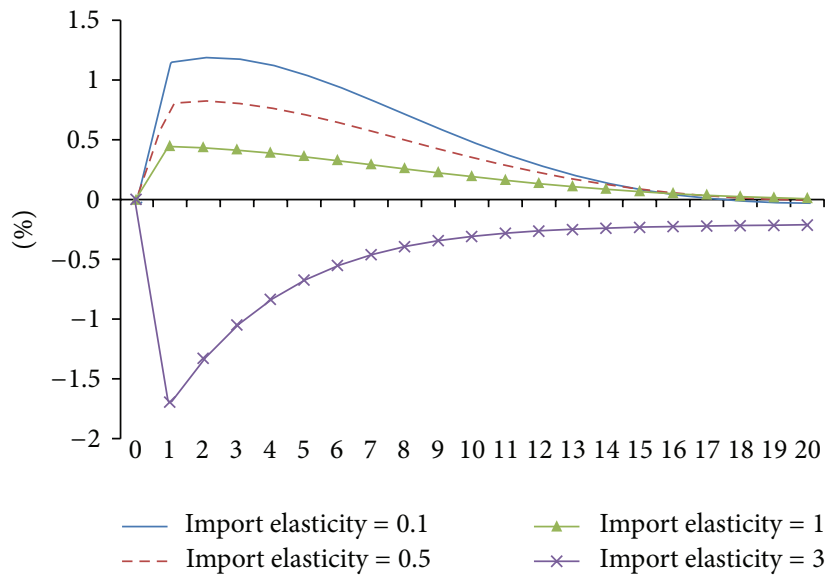

FIGURE 2: Impulse responses of regional output to the local government spending shock.

elasticity (Figure 2). Note that in our small-region model, the crowding-out effect in terms of international net export, as in the traditional Mundell-Fleming model in which a flexible exchange rate system is adopted, does not exist. This can be true if we incorporate international trade. This is a notable feature for a small-region economy.

4.2. Central Government's Spending Shock. In our settings, the central government's spending and the local government's spending have an equivalent effect for output because local debt does not affect a small region's economy other than 

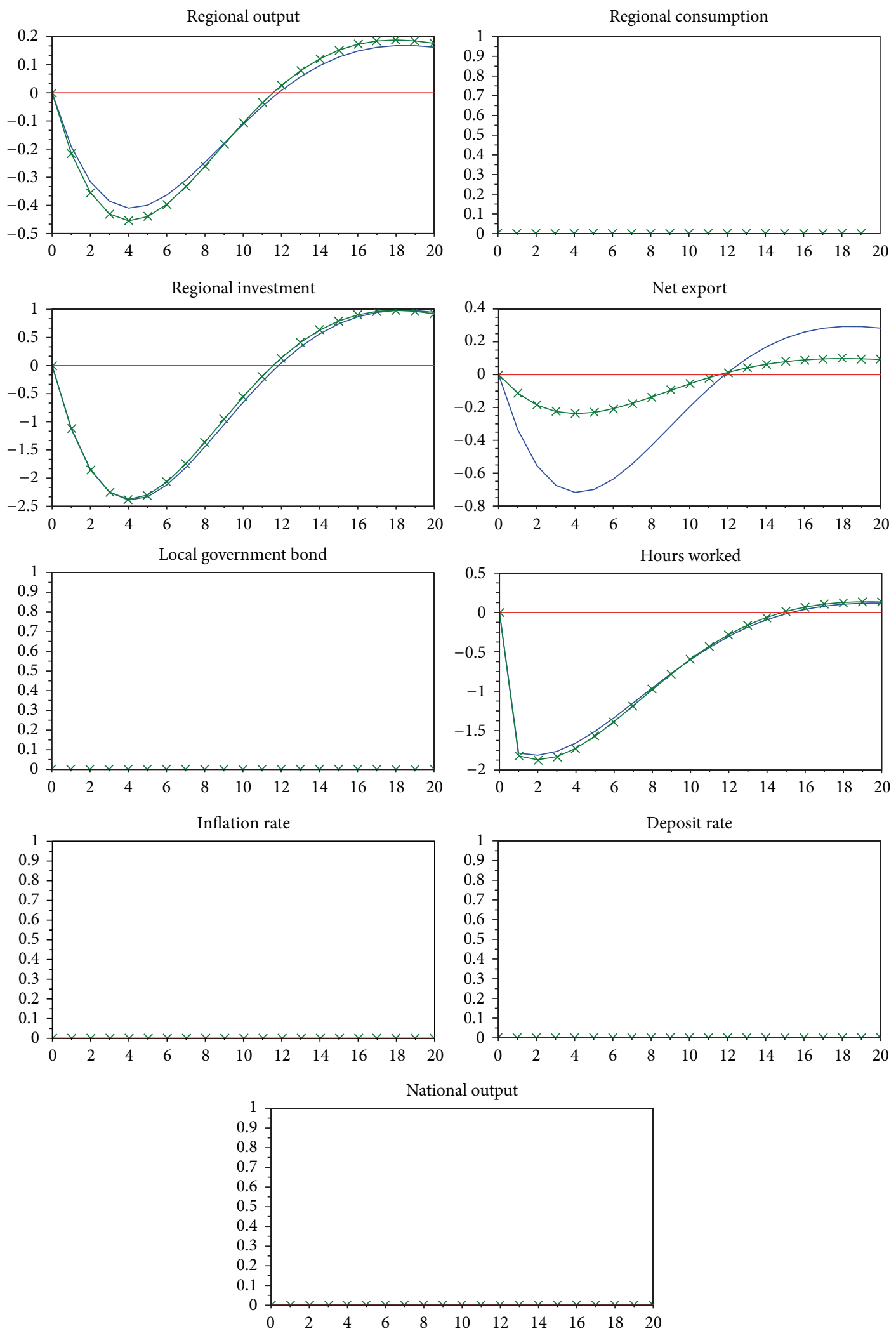

- Import elasticity $=0.3$

$x * x$ Import elasticity $=0.1$

FIGURE 3: Impulse responses to the regional technology shock. Note: each line represents a percentage deviation from the steady state value. 

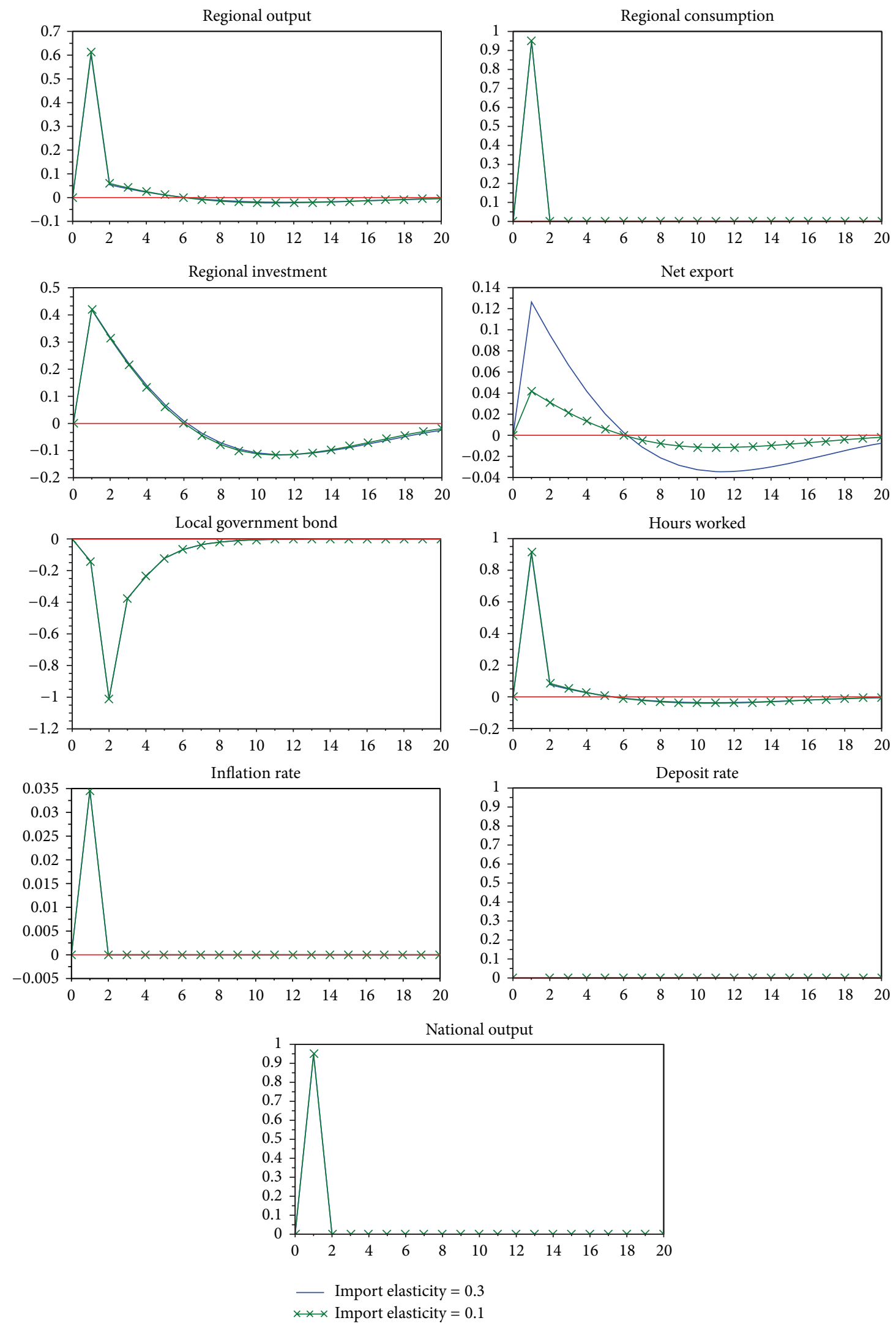

FIGURE 4: Impulse responses to the monetary shock. Note: each line represents a percentage deviation from the steady state value. 

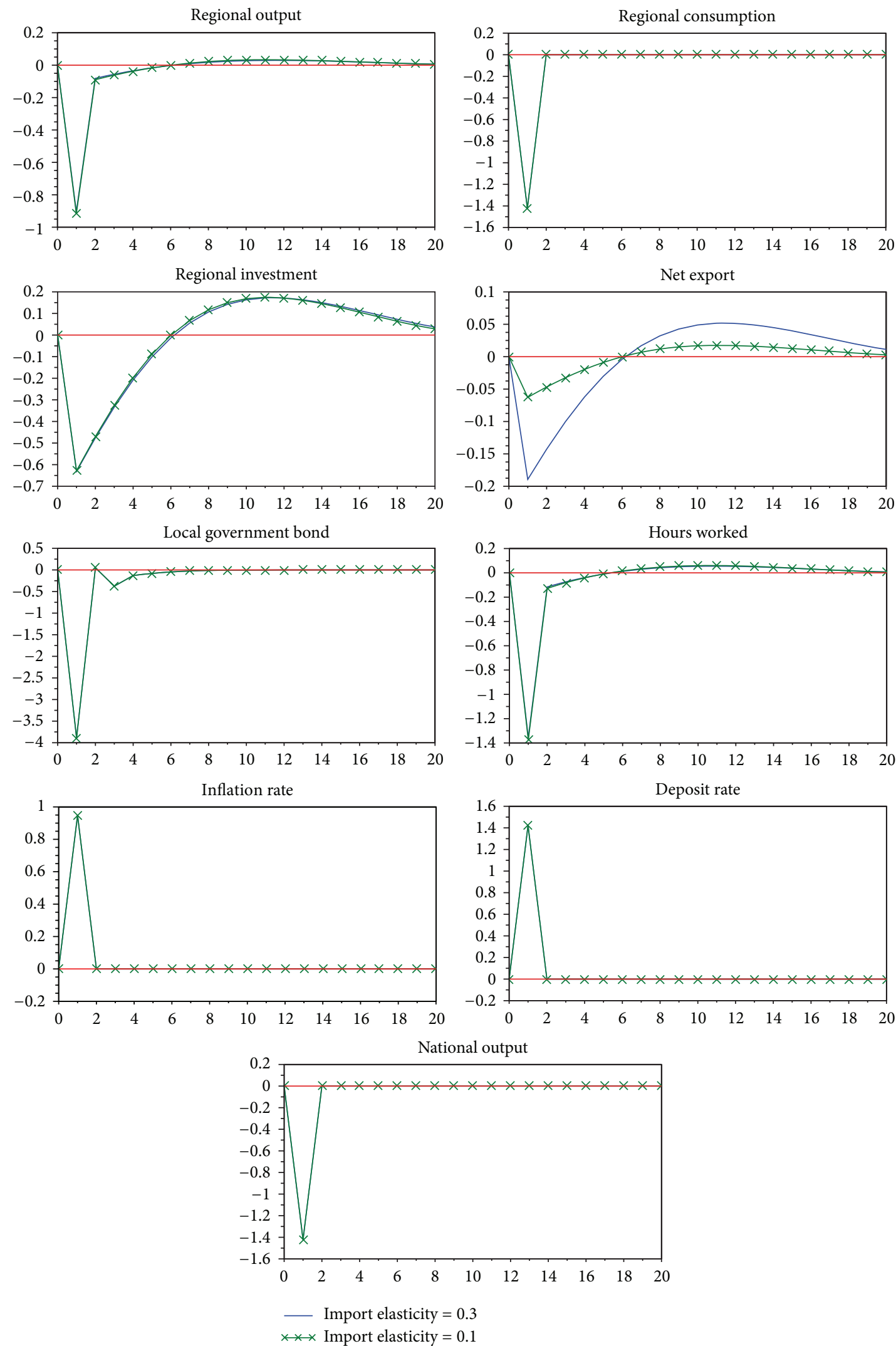

FIGURE 5: Impulse responses to the macroeconomic supply shock. Note: each line represents a percentage deviation from the steady state value. 
through the local tax and local bond rates. (Therefore, we omitted the figure of impulse responses.) However, if nonRicardian households exist as in Galí et al. [5] and central debt and local debt have a different risk premium, a difference emerges. The increase in government's spending raises the bond rate. This leads to a higher tax rate, and therefore, if governments have different elasticity of tax with respect to bonds, it yields the different consequences.

\section{Model Properties}

In this section, we check our model's properties from a numerical simulation to investigate other shocks.

5.1. Regional Technology Shock. Figure 3 shows the impulse responses to the $1 \%$ technology shock $z_{t}$ in (1). Advances in technology first decrease the region's output because the increase in wholesale goods decreases prices and this leads to a decrease in the labor demand through a rise in markup. The nominal interest rate does not change because the national economy is not affected by a change in the small economy, and this results in the labor supply being unchanged. However, output increases later. This is because advanced technology raises the marginal output of capital and investment increases with a rise in value of capital.

5.2. Monetary Policy Shock. Figure 4 shows the impulse responses to the $1 \%$ monetary policy shock $\varepsilon_{t}^{R}$ in (18). The decline of the nominal interest rate boosts consumption and investment in the small region (in addition to national consumption). Furthermore, in a small region, export to other regions rises because of the increase in GDP. This has a positive effect on output in the small region.

5.3. Macroeconomic Supply Shock. Figure 5 shows the impulse responses to the $1 \%$ of supply shock $\varepsilon_{t}^{s}$ in (17). This shock can be considered as a positive TFP shock. The decrease in inflation leads to a decrease in the nominal interest rate through the monetary policy rule and therefore GDP increases. In turn, since the small region's investment rises, its output also increases. However, deflation increases the real interest rate and later investment decreases.

\section{Concluding Remarks}

This paper constructs a tractable DSGE model for a regional economy that is considered small because it does not affect its national economy. To examine properties of our small-region DSGE model, we conduct several numerical simulations. As a notable result, regional fiscal expansion is larger than that in standard DSGE models. This is because the increase in regional output does not raise interest rates, and this leads to crowding-in effects of investment. However, this property disappears as import elasticity rises, because the increase in demand for investment is canceled out by the increase in import. Therefore, the value of the import elasticity is crucial for the regional fiscal multiplier. These findings bear important implications especially for small local government policy planners if they implement fiscal policy in order to boost their region's economy.

\section{References}

[1] M. Baxter and R. G. King, "Fiscal Policy in general equilibrium," American Economic Review, vol. 92, pp. 571-589, 1993.

[2] M. O. Ravn, S. Schmitt-Gorohe, and M. Uribe, "Deep habits," Review of Economic Studies, vol. 73, pp. 195-218, 2006.

[3] L. Linnemann, "The effect of government spending on private consumption: a puzzle?" Journal of Money, Credit and Banking, vol. 38, no. 7, pp. 1715-1735, 2006.

[4] T. Monacelli, R. Perotti, and A. Trigari, "Unemployment fiscal multipliers," Journal of Monetary Economics, vol. 57, no. 5, pp. 531-553, 2010.

[5] J. Galí, J. Valles, and J. D. Lopez-Salido, "Understanding the effects of government spending on consumption," Journal of the European Economic Association, vol. 5, pp. 227-250, 2007.

[6] L. Christiano, M. Eichenbaum, and S. Rebelo, "When is the government spending multiplier large?" Journal of Political Economy, vol. 119, no. 1, pp. 78-121, 2011.

[7] R. Beetsma and M. Giuliodori, "The effects of government purchases shocks: review and estimates for the EU," Economic Journal, vol. 121, no. 550, pp. F4-F32, 2011.

[8] L. J. Christiano, M. Trabandt, and K. Walentin, "Introducing financial frictions and unemployment into a small open economy model," Journal of Economic Dynamics and Control, vol. 35, no. 12, pp. 1999-2041, 2011.

[9] M. Adolfson, S. Laséen, J. Lindé, and M. Villani, "Evaluating an estimated new Keynesian small open economy model," Journal of Economic Dynamics and Control, vol. 32, pp. 2690-2721, 2008.

[10] S. M. Cakici, "Financial integration and business cycles in a small open economy," Journal of International Money and Finance, vol. 30, no. 7, pp. 1280-1302, 2011.

[11] B. De Paoli, "Monetary policy and welfare in a small open economy," Journal of International Economics, vol. 77, no. 1, pp. 11-22, 2009.

[12] G. A. Calvo, "Staggered prices in a utility-maximizing framework," Journal of Monetary Economics, vol. 12, no. 3, pp. 383398, 1983.

[13] S. Schmitt-Grohé and M. Uribe, "Closing small open economy models," Journal of International Economics, vol. 61, no. 1, pp. 163-185, 2003.

[14] L. J. Christiano, M. Eichenbaum, and C. L. Evans, "Nominal rigidities and the dynamic effects of a shock to monetary policy," Journal of Political Economy, vol. 113, no. 1, pp. 1-45, 2005.

[15] A. T. Levin, A. Onatski, J. C. Williams, and N. Williams, "Monetary policy under uncertainty in micro-founded macroeconometric models," NBER Macroeconomics Annual, vol. 20, pp. 229-287, 2005. 


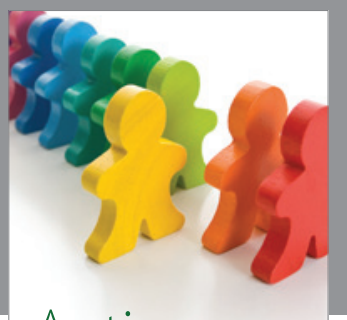

Autism

Research and Treatment
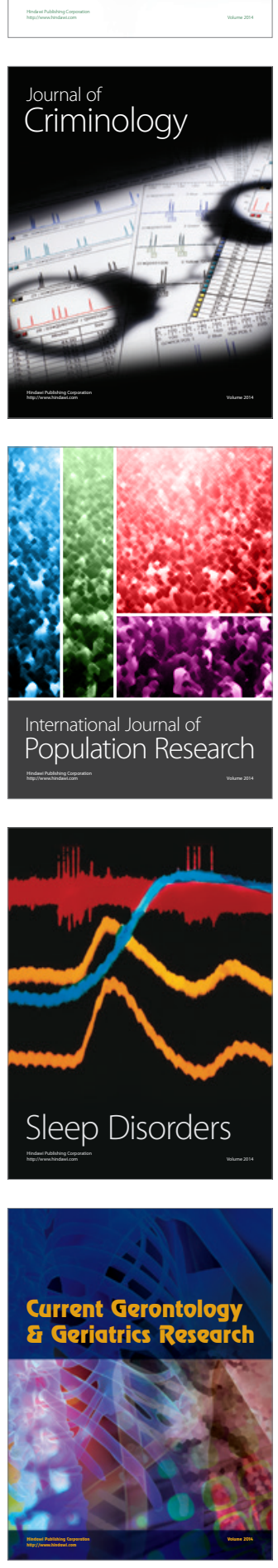
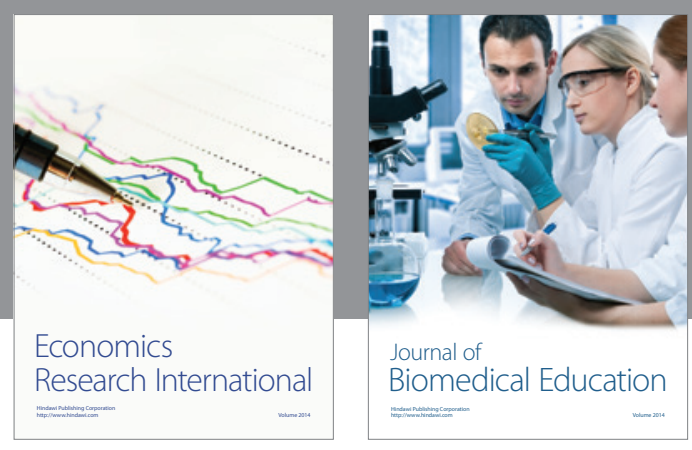

Journal of

Biomedical Education

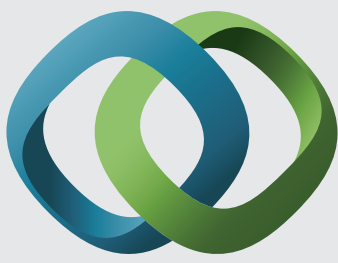

\section{Hindawi}

Submit your manuscripts at

http://www.hindawi.com
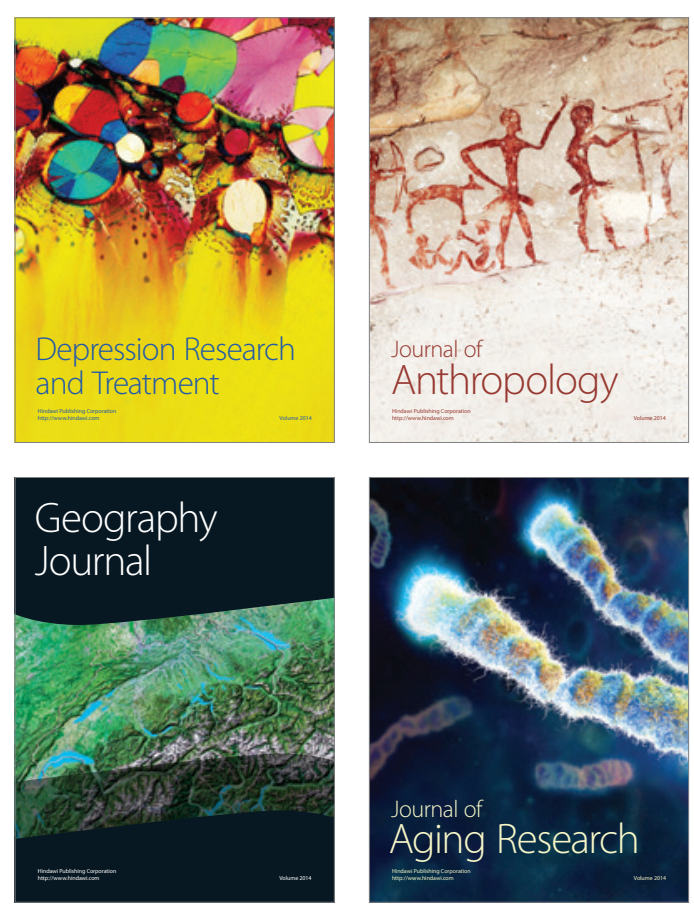

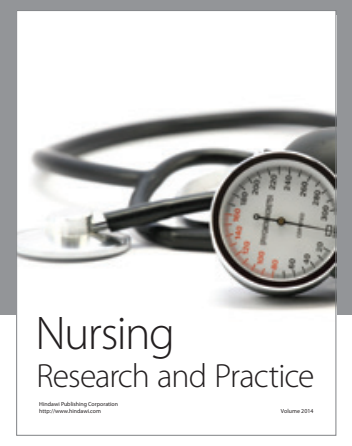

Nursing

Research and Practice

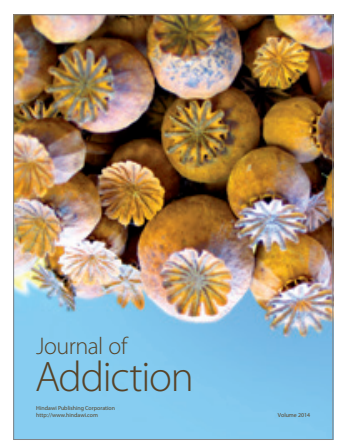

Child Development

Research

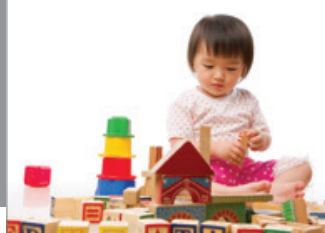

迥
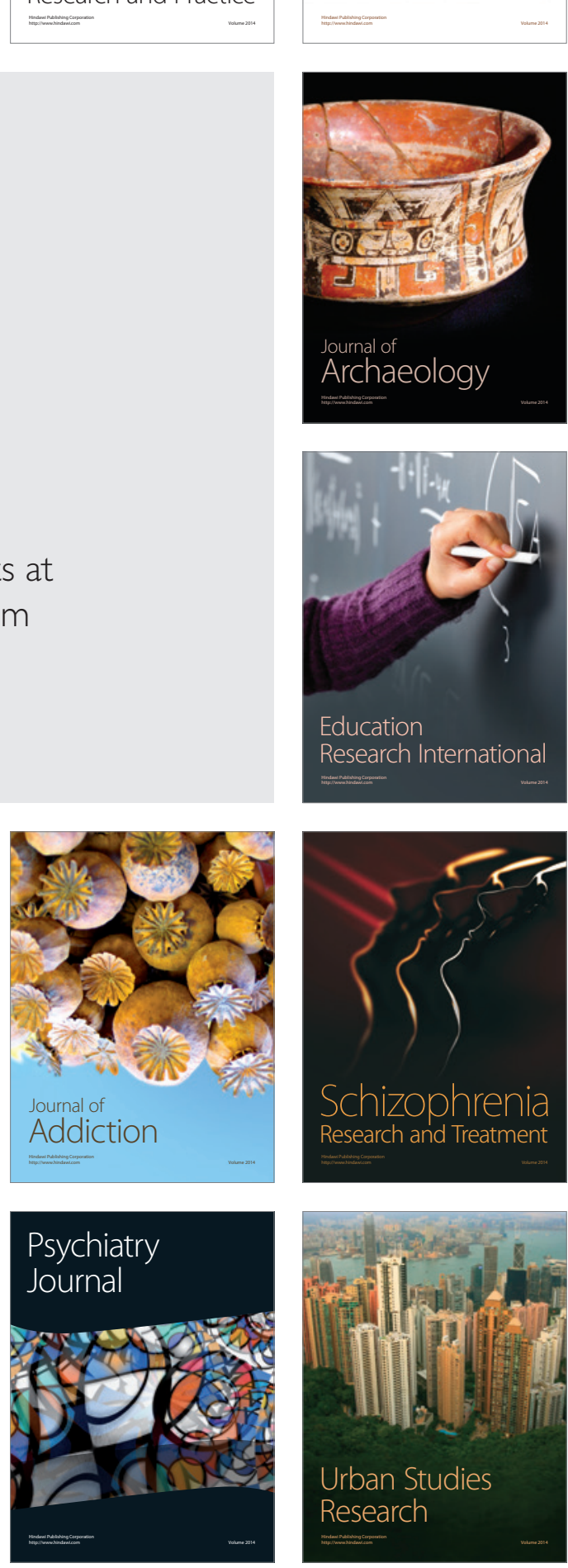